\title{
The Creep Parameters of SAC305 Unleaded Solders
}

\author{
Chao-Ming Hsu, ${ }^{1}$ Ah-Der Lin, ${ }^{2}$ and Jao-Hwa Kuang ${ }^{3}$ \\ ${ }^{1}$ Department of Mechanical Engineering, National Kaohsiung University of Applied Sciences, Kaohsiung 80778, Taiwan \\ ${ }^{2}$ Department of Mechanical Engineering, Cheng Shiu University, Kaohsiung 83347, Taiwan \\ ${ }^{3}$ Department of Mechanical and Electromechanical Engineering, National Sun Yat-sen University, Kaohsiung 80424, Taiwan
}

Correspondence should be addressed to Jao-Hwa Kuang; kuang@mail.nsysu.edu.tw

Received 14 September 2013; Accepted 16 October 2013

Academic Editor: Shoou-Jinn Chang

Copyright (c) 2013 Chao-Ming Hsu et al. This is an open access article distributed under the Creative Commons Attribution License, which permits unrestricted use, distribution, and reproduction in any medium, provided the original work is properly cited.

\begin{abstract}
The tensile and shear loading creep parameters of unleaded $\mathrm{Sn} / 3.0 \mathrm{Ag} / 0.5 \mathrm{Cu}$ solders are extracted from the proposed tensile and shear creep tests in this work. Four creep loading temperatures, that is, $120^{\circ}, 135^{\circ}, 150^{\circ}$, and $165^{\circ} \mathrm{C}$, are employed to extract the corresponding parameters. The creep parameters for tensile and shear loading models, that is, stress exponent, material constant, and activation energy, are curve-fitted by using the least square error and simplex optimization algorithms. The accuracy of the extracted parameters correlated with the measured strain rate versus temperature curves. Results indicate that the proposed measurement setup and extraction algorithm is feasible to extract the tensile and shear type creep parameters with good accuracy.
\end{abstract}

\section{Introduction}

The unleaded $\mathrm{Sn} / 3.0 \mathrm{Ag} / 0.5 \mathrm{Cu}$ solders have been used widely in electronic and photonic device packaging. The high operation temperature and on-off thermal cycling introduced in the electronic and photonic devices may introduce the serve thermal creep deformation. The creep deformation may lead to fiber alignment shifts in the transceiver module connectors and reduce the signal efficiency dramatically in the optical communication system. Damage to the encapsulation of electronic components may also be caused by thermal mechanical fatigue (TMF) at the welding point due to creep of the intermetallic compound. Various electronic component materials have different mechanical and thermal properties. Correspondingly, the creep deformation introduced from various temperature distributions may facilitate a redistribution of the stress status around a weld, which may eventually lead to a fatigue failure. A number of studies have investigated thermal stress to make predictions for the timespan of thermal fatigue at the welding areas of components under various thermal cycle loads.

Damage to electronic encapsulations occurs frequently near the solder joint due to thermal fatigue and creep. Creep only occurs when an object is subjected to high temperatures for a prolonged period of time, and creep deformation is generally induced mainly by two factors: temperature and stress. Developing a creep model for electronic encapsulation materials is a very important issue. This study proposed two creep experiments, that is, the tensile and the shear loading creep tests, to derive the corresponding creep equations. Different loading temperatures are applied to initiate the creep for different $\mathrm{Sn} / 3.0 \mathrm{Ag} / 0.5 \mathrm{Cu}$ solder specimens.

From 1990 to 2002, Lau et al. [1-7] published a number of papers to consolidate the temperature change correlations associated with electronic packaging materials and explored the relationships between the materials and the stress/strain. Morris Jr. et al. [8] discussed the properties of melting point of two alloys, tin-beryllium (Sn-Bi) and tin-lead $(60 \mathrm{Sn} / 40 \mathrm{~Pb})$, used in electronic packaging engineering. Yang et al. [9-11] found that the eutectic microstructure of $\mathrm{Sn} / 3.5 \mathrm{Ag}$ solder balls works better in laser reflow welding than in the infrared reflow process. Vianco [12-16] studied the stress-strain and creep effects in various tin-ball materials, including tinlead (Sn63/Pb37), tin-silver-beryllium (Sn-Ag-Bi), and tinsilver-copper-antimony ( $\mathrm{Sn}-\mathrm{Ag}-\mathrm{Cu}-\mathrm{Sb})$, used in encapsulation. Recently, the unleaded solder materials have been of interest for all electronic device manufacturers. The unleaded $\mathrm{Sn} / 3.0 \mathrm{Ag} / 0.5 \mathrm{Cu}$ solder is the most popular one. 


\section{Creep Experiments on $\mathrm{Sn} / 3.0 \mathrm{Ag} / 0.5 \mathrm{Cu}$ Solder Material}

Creep deformation and its induced strain and strain rate are tested with a constant loading temperature. The loading temperature is higher than one half of the melting temperature of the specimen material. As noted in many textbooks, the creep deformation can be divided in three stages. In the first stage, that is, the primary creep stage, the more active dislocation sources in the material continue their activities, but they will gradually be blocked thus gradually reducing the strain rate. In the second stage, that is, the secondary creep stage, the strain hardening and recovery achieve equilibrium, so that the strain rate is maintained at a constant value; the minimum creep rate is reached at this stage. In the third stage, that is, the so-called tertiary creep stage [17], necking, voids, or cracks appear and the material is weakened by overaging and high temperature oxidation, thus increasing the strain rate. The creep rate increases with temperature and stress.

In this study two specimens of $\mathrm{Sn} / 3.0 \mathrm{Ag} / 0.5 \mathrm{Cu}$ solder material are used to test the creep phenomena in tensile and shear loading conditions. Four loading temperatures have been applied to measure the elongation variation with a constant load. The corresponding strain and strain rate variations have also been derived.

2.1. Creep Model. As noted [17], the creep strain $(\varepsilon)$ in the material is dominated by the loading stress $(\sigma)$, stress time $(t)$, and temperature $(T)$; that is,

$$
\varepsilon=\varepsilon(\sigma, T, t) .
$$

For simplicity, the interaction between these parameters is ignored.

The Norton power law has been used widely to describe the secondary stage creep deformation. In this study, the Norton model has also been employed to describe the secondary stage creep phenomena as the specimen subjected to a tensile or shear type loading. The tensile and shear type creep models are

$$
\begin{aligned}
& \dot{\varepsilon}=A \sigma^{n} e^{-\mathrm{Q} / \mathrm{RT}}, \\
& \dot{\gamma}=B \tau^{m} e^{-\mathrm{Q} / \mathrm{RT}},
\end{aligned}
$$

where $A$ and $B$ are the material constant, $\sigma$ is the average normal stress $(\mathrm{MPa}), \tau$ is the average shear stress $(\mathrm{MPa})$, $Q$ is the activation energy $(\mathrm{J} / \mathrm{mol}), R$ is the gas constant $\left(8.3 \mathrm{~mol}^{-1} \mathrm{~K}^{-1}\right), T$ is the absolute temperature $(\mathrm{K})$, and $n$ and $m$ are the stress exponent under tensile and shear loads, respectively.

Taking the logarithm on both sides of (2), it leads to a linear relation between the $\ln \dot{\varepsilon}$ and $\ln \sigma$ for a constant loading temperature:

$$
\ln \dot{\varepsilon}=\left(\ln A-\frac{\mathrm{Q}}{\mathrm{RT}}\right)+n \ln \sigma .
$$

Similarly, the shear strain rate can be derived as

$$
\ln \dot{\gamma}=\left(\ln B-\frac{\mathrm{Q}}{\mathrm{RT}}\right)+m \ln \tau \text {. }
$$

In the equations, $A$ and $B$ are temperature functions:

$$
\begin{gathered}
A=\alpha+\beta e^{\omega T}, \\
B=\kappa+\zeta e^{\delta T},
\end{gathered}
$$

where $(\alpha, \beta, \omega$, and $n)$ and $(\kappa, \zeta, \delta$, and $m)$ are creep parameter sets of the tensile and shear models, respectively. $Q$ and $R$ are the activation energy and gas constant of the solder. From (4) and (5), it is observed that the logarithm $\ln \dot{\varepsilon}$ (or $\ln \dot{\gamma}$ ) of strain rate assumes a linear relationship with the $\operatorname{logarithm}$ value of average stress $\ln \sigma$ (or $\ln \tau$ ). The constant slopes of $\ln \dot{\varepsilon}$ versus $\ln \sigma$ and $\ln \dot{\gamma}$ versus $\ln \tau$ are the respective stress exponents $n$, and $m$. The natural logarithm of strain rate $(\ln \dot{\varepsilon}, \ln \dot{\gamma})$ is proportional to the reciprocal of loading temperature $(1 / T)$ [18]. Therefore, the activation energy parameter $Q$ can then be derived from the relationship between the natural logarithm of the strain rate and the reciprocal of the temperature.

Based on the extraction algorithm mentioned in the previous section, the values of creep parameters $\alpha, \beta, \omega, \kappa, \zeta, \delta, n, m$, and $Q$ can be extracted from the measured strain rate and loading stress by employing the simplex optimization method in this work.

2.2. Creep Experiment Setup and Specimens. The tensile and shear creep specimens are illustrated in Figures 1(a) and 1(b). Two round copper solid bars are welded with the $\mathrm{Sn} / 3.0 \mathrm{Ag} / 0.5 \mathrm{Cu}$ solder between the orthogonal or parallel connecting surfaces. Figures 2(a) and 2(b) show the preparation and geometries of the specimens used in the tensile and shear creep tests. An appropriate amount of the $\mathrm{Sn} / 3.0 \mathrm{Ag} / 0.5 \mathrm{Cu}$ solder paste was placed at the middle section of two $5 \mathrm{~mm}$ in diameter copper rods. About 3$4 \mathrm{~mm}$ gap is designed for the $\mathrm{Sn} / 3.0 \mathrm{Ag} / 0.5 \mathrm{Cu}$ solder layer. These two copper rods were then, respectively, placed on a vertical clamp or a "V" shape bed, as shown in Figure 1(a) or Figure 1(b), respectively. A torch was then used to heat the area around the $\mathrm{Sn} / 3.0 \mathrm{Ag} / 0.5 \mathrm{Cu}$ solder paste until it was completely molten. Extra care was taken not to directly expose the solder paste to the flame. The dimensions of eight $\mathrm{Sn} / 3.0 \mathrm{Ag} / 0.5 \mathrm{Cu}$ solder specimens are listed in Table 1 . The size parameters $A, B, C$, and $D$ of eight solder specimens (specimens numbers 1a 8a) indicate the diameters of top, bottom, waist, and the height of the solder layer in the tensile specimens. Due to the surface tension introduced in the melting process, the waist diameter $C$ in the tensile specimens always has the smallest value. The corresponding size parameters $E, F$, and $G$ for the eight shear specimens (specimens numbers $1 \mathrm{~b} \sim 8 \mathrm{~b}$ ) values, respectively, indicate the length, width, and height of the solidified solder paste. Two constant loads, that is, 7.35 and $29.4 \mathrm{~N}$, are applied for the tensile and shear creep tests, and four loading temperatures, that is, $120,135,150$, and $165^{\circ} \mathrm{C}(393,408,423$, and $438 \mathrm{~K})$, are measured in this study. Since the melting temperature of the copper is much higher than that of the $\mathrm{Sn} / 3.0 \mathrm{Ag} / 0.5 \mathrm{Cu}$ solder, the creep deformation of the copper bar can be ignored in these measurements. In other words, the measured end 

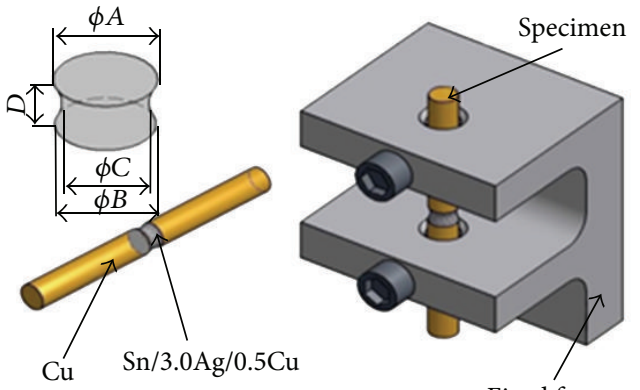

Fixed frame

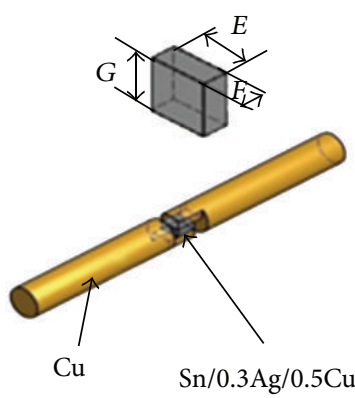

$\mathrm{Sn} / 0.3 \mathrm{Ag} / 0.5 \mathrm{Cu}$

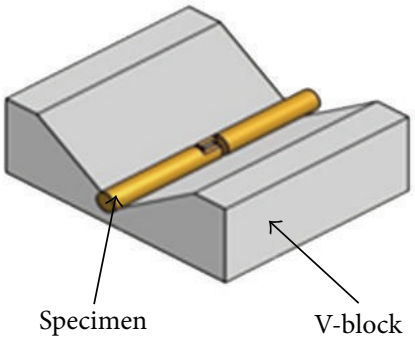

(b)

(a)

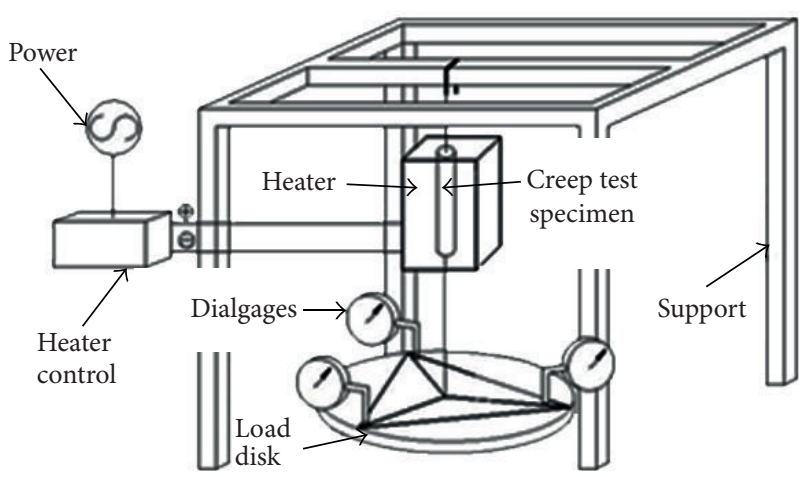

(c)

FIGURE 1: Creep experiment setup and specimens arrangement: (a) tensile creep specimen, (b) shear creep specimen, and (c) creep experiment setup.

TABLE 1: Creep specimen parameters.

\begin{tabular}{|c|c|c|c|c|c|c|c|c|c|}
\hline \multirow{2}{*}{ Specimens no. } & \multirow{2}{*}{ Load $(\mathrm{N})$} & \multirow{2}{*}{ Temp. (K) } & \multicolumn{7}{|c|}{ Dimensions of Specimens (mm) } \\
\hline & & & $A$ & $B$ & $C$ & $D$ & $E$ & $F$ & $G$ \\
\hline $1 \mathrm{a}, 1 \mathrm{~b}$ & \multirow{4}{*}{7.35} & 393 & 4.4 & 4.2 & 3.7 & 4.0 & 1.6 & 0.7 & 4.7 \\
\hline $2 a, 2 b$ & & 405 & 3.9 & 4.0 & 2.9 & 4.0 & 2.2 & 0.6 & 4.7 \\
\hline $3 a, 3 b$ & & 423 & 4.0 & 3.8 & 3.0 & 3.6 & 1.8 & 0.6 & 4.0 \\
\hline $4 a, 4 b$ & & 438 & 4.8 & 4.5 & 2.7 & 3.8 & 1.4 & 0.6 & 4.4 \\
\hline $5 a, 5 b$ & \multirow{4}{*}{29.4} & 393 & 3.8 & 3.8 & 3.2 & 3.4 & 1.8 & 0.8 & 2.2 \\
\hline $6 a, 6 b$ & & 405 & 4.4 & 3.9 & 3.5 & 3.2 & 1.8 & 0.7 & 2.6 \\
\hline $7 a, 7 b$ & & 423 & 4.8 & 4.6 & 3.6 & 3.2 & 2.2 & 0.8 & 2.2 \\
\hline $8 \mathrm{a}, 8 \mathrm{~b}$ & & 438 & 4.8 & 4.4 & 3.6 & 3.4 & 2.1 & 0.8 & 2.4 \\
\hline
\end{tabular}

displacements are considered to be introduced from the creep deformation of the solder layer.

Figure 2(c) is the scheme of the creep test setup. The specimens are arranged in a temperature controlled box and loaded vertically with a constant disc weight. Three displacement sensors are located at three measured points. The measured elongation variation in the loading direction is recorded periodically. The corresponding true stress, strain, and strain rate are calculated simultaneously.

\section{Experimental Results and Creep Parameters Extraction}

Two sets of creep specimens, that is, eight specimens for the tensile creep test and the other eight specimens for the shear creep test, are measured with two constant loads (7.53 and $29.4 \mathrm{~N}$ ) and four loading temperatures (393, 408, 423, and $438 \mathrm{~K}$ ). Since the specimens' sizes are not identical, each specimen has a different sectional dimension. The corresponding loading stress should also be different; therefore, the experiment was expected to record a set of primary data with different values for stress, temperature, and timeshift. To compensate the possible displacement measurement error, the vertical displacements $d_{A}, d_{B}$, and $d_{C}$ measured at disk rim as shown in Figure 3 are averaged. The vertical displacement of the specimens is averaged as

$$
d=\frac{\left(d_{A}+d_{B}+d_{C}\right)}{3} .
$$

3.1. Tensile Creep Experiment. Figure 4 shows the variation of displacement of tensile specimens subjected to the loads 


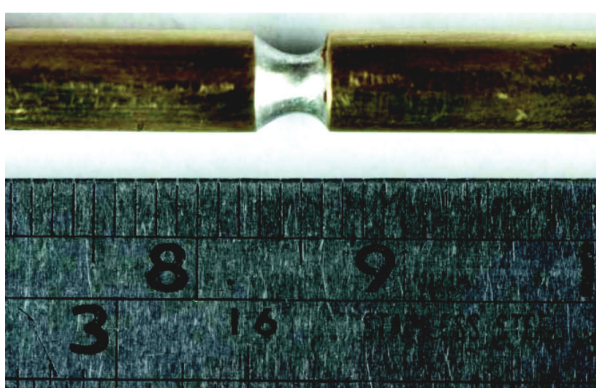

(a)

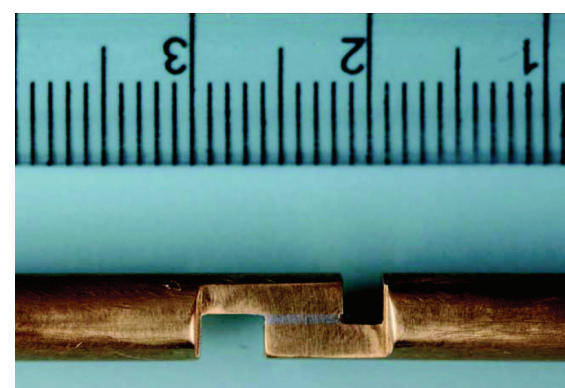

(b)

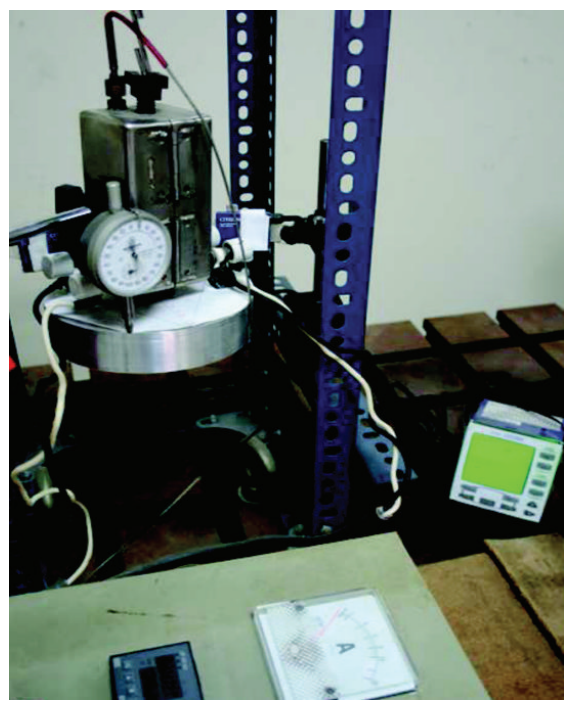

(c)

FIGURE 2: Creep experiment specimen and equipment: (a) tensile creep experiment specimen, (b) shear creep experiment specimen, and (c) creep experiment equipment.

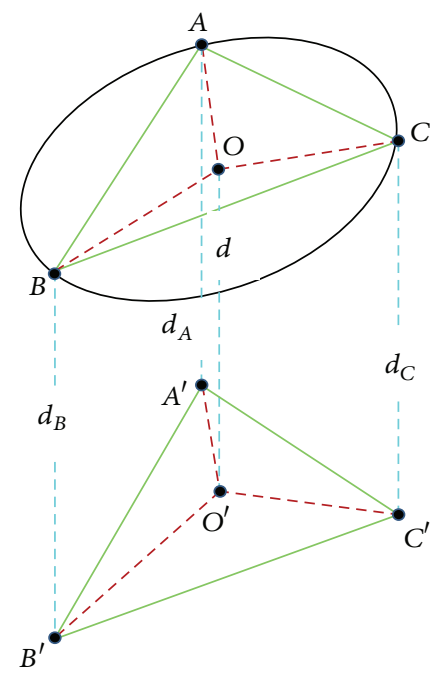

FIgURE 3: Measuring displacement.

of 7.35 and 29.4 N. For the case of specimens subjected to a load of $7.35 \mathrm{~N}$ with a loading temperature $438 \mathrm{~K}$ as shown in Figure 4 , the specimens took about 0.45 hour to go through the primary creep stage. The two levels of loadings are chosen to make sure that the tested specimens can reach the state of secondary creep. For example, the normal stress induced in the specimens with a $29.4 \mathrm{~N}$ loading is $26.8 \mathrm{MPa}$, which is about $60 \%$ of the yielding strength of the tested solder. The end of tested specimens was measured to have a displacement of $0.02 \mathrm{~mm}$ in this period. The measured results for the same specimens reveal a secondary creep stage from loading time 0.45 to 20.83 hours. The extension displacement increases from $0.2 \mathrm{~mm}$ to $0.024 \mathrm{~mm}$ with an almost constant speed. The third stage creep occurred after 20.83 hours. The measured results indicate that the creep deformation of the $\mathrm{Sn} / 3.0 \mathrm{Ag} / 0.5 \mathrm{Cu}$ solder is quite sensitive to the loading temperature. Figure 5 shows the corresponding variation curves of strain and strain rate of the tensile specimens with a loading condition of $7.35 \mathrm{~N}$ and $438 \mathrm{~K}$ during the creep test. An average strain rate of $7.95 \times 10^{-7} 1 / \mathrm{sec}$ was measured for the specimens in the secondary creep stage. Table 2 lists the measured average strain rates $\dot{\varepsilon}$ of these eight measured tensile specimens, that is, tensile specimens numbers 1(a) to $8(\mathrm{a})$, in this work.

Equation (4) reveals that the creep parameter of activation energy $Q$ can be derived from the slope of algorithm value $(\ln \dot{\varepsilon})$ and $(1 / T)$ diagram. Results in Figure 6 show the 


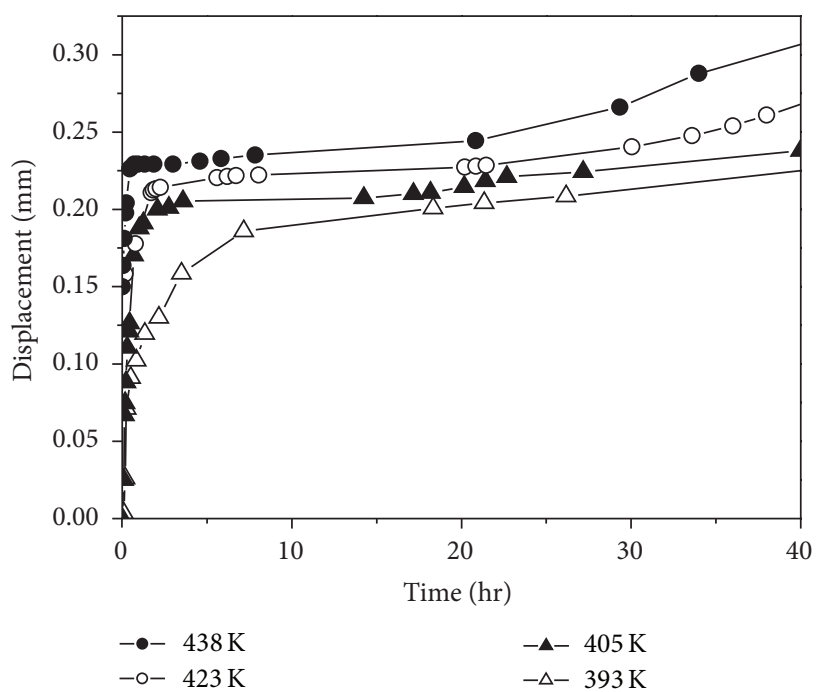

(a)

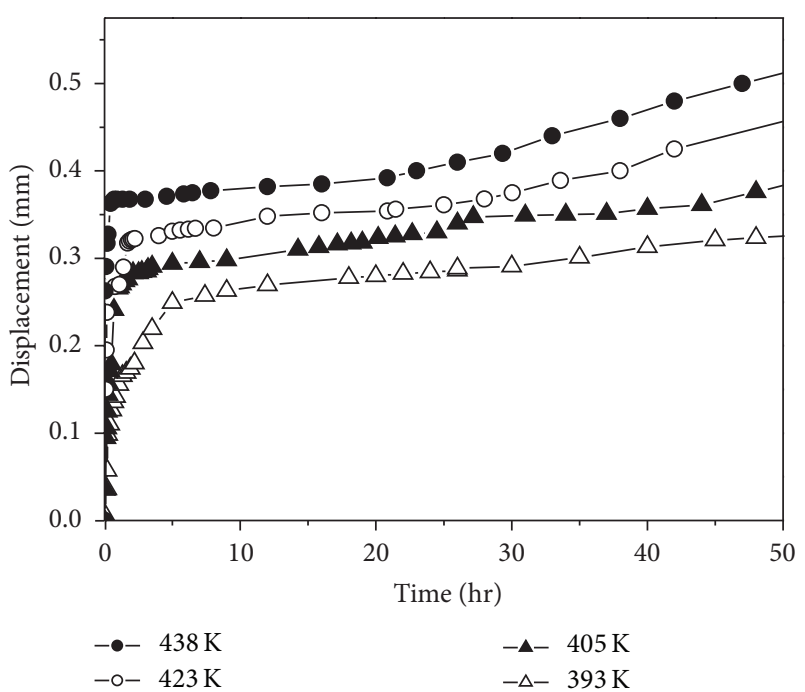

(b)

FIGURE 4: Correlation of displacement-time in the tensile creep experiment under different loads: (a) $7.35 \mathrm{~N}$ load disc and (b) $29.4 \mathrm{~N}$ load disc.

TABLE 2: Results of tensile creep specimen experiment.

\begin{tabular}{lcccc}
\hline No. & Load $(\mathrm{N})$ & Temp. $(\mathrm{K})$ & Average stress $(\mathrm{MPa})$ & Strain rate $\left(\times 10^{-6} 1 / \mathrm{sec}\right)$ \\
\hline 1 & & 393 & 0.669 & 0.0854 \\
2 & 7.35 & 405 & 1.145 & 0.336 \\
3 & & 423 & 1.076 & 0.506 \\
4 & & 438 & 1.266 & 0.795 \\
\hline 5 & & 393 & 3.657 & 1.28 \\
6 & 29.4 & 405 & 3.057 & 2.10 \\
7 & 423 & 2.890 & 3.87 \\
8 & & 438 & 3.057 & 6.12 \\
\hline
\end{tabular}

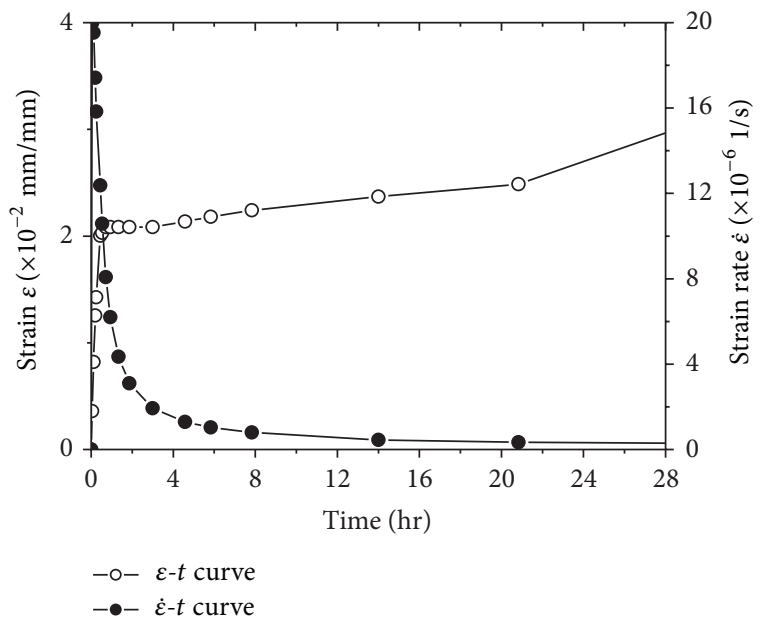

FIGURE 5: Correlation of strain-time and strain rate in the tensile creep experiment under a temperature of $438 \mathrm{~K}$ and a load of $7.34 \mathrm{~N}$.

correlation between $\ln \dot{\varepsilon}$ and $1 / T$ of tested specimens under the loads of $7.35 \mathrm{~N}$ and 29.4 N. Based on Norton power law, that is, (4), the slope value is equal to $-Q / R$. By applying the least square error method, the linear slope values of measured specimens under loads of $7.35 \mathrm{~N}$ and $29.4 \mathrm{~N}$ can be derived as -8318.02 and -7257.00 , respectively. The average value -7737.51 of these two slopes and an activation energy value $64221.32(\mathrm{~J} / \mathrm{mol})$ can be derived with the gas constant $\left(8.3 \mathrm{~mol}^{-1} \mathrm{~K}^{-1}\right)$.

Figure 7 shows the correlation between the logarithm strain rate $(\ln \dot{\varepsilon})$ and the logarithm stress $(\ln \sigma)$ in the tensile creep experiment. The four left points and the four right points in this figure are related to the measured data for the load of $7.35 \mathrm{~N}$ and $29.4 \mathrm{~N}$, respectively. Therefore, four linear equations can be derived for these tensile specimens to describe the power law relation between the strain rate and average stress with different loading temperatures. They are

$$
\begin{aligned}
& \ln \dot{\varepsilon}=1.59(\ln \sigma)-14.94 \quad \text { when } T=393 \mathrm{~K}, \\
& \ln \dot{\varepsilon}=1.87(\ln \sigma)-14.46 \quad \text { when } T=408 \mathrm{~K}, \\
& \ln \dot{\varepsilon}=2.06(\ln \sigma)-13.95 \quad \text { when } T=423 \mathrm{~K}, \\
& \ln \dot{\varepsilon}=2.30(\ln \sigma)-13.59 \quad \text { when } T=438 \mathrm{~K} .
\end{aligned}
$$




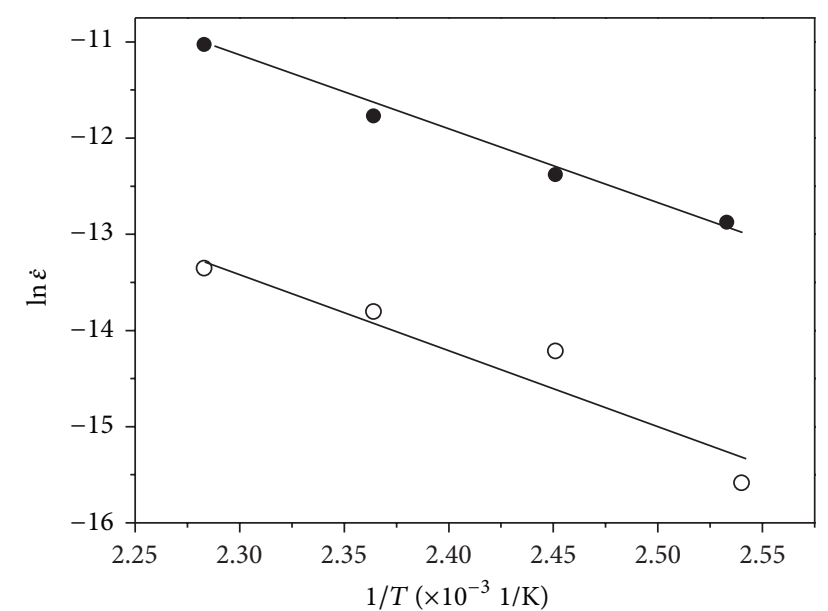

- $29.4 \mathrm{~N}$

○ $7.35 \mathrm{~N}$

FIGURE 6: Natural logarithm of the tensile creep experiment strain rate and reciprocal to temperature.

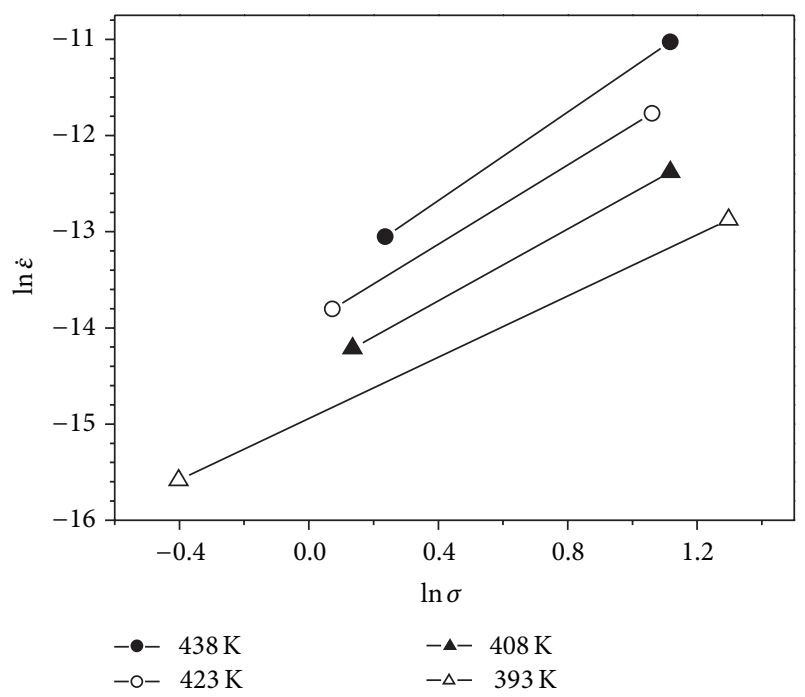

FIGURE 7: The correlation between logarithm strain rate and logarithm stress.

Initially, an average slope value of $n$ (1.954) is approximated from these four equations by ignoring its loading temperature effect. Similarly, a constant value of -14.22 is approximated by averaging the four constant values in (8). Then an approximated initial trial power relation for these tensile specimens is proposed; that is,

$$
\ln \dot{\varepsilon}=1.954 \quad \ln \sigma-14.22 \text {. }
$$

From (4) and (9) and the approximated activation energy value $64221.32(\mathrm{~J} / \mathrm{mol})$ mentioned previously, the relationship between the material constant $A$ and temperature can be derived in Figure 8. By using the least square error method and the definition of material constant $A$ in (6), the set of parameters in the tensile creep equation can be derived as $\alpha=15.40, \beta=6.39 \times 10^{11}$, and $\omega=(-1 / 18.04)$.

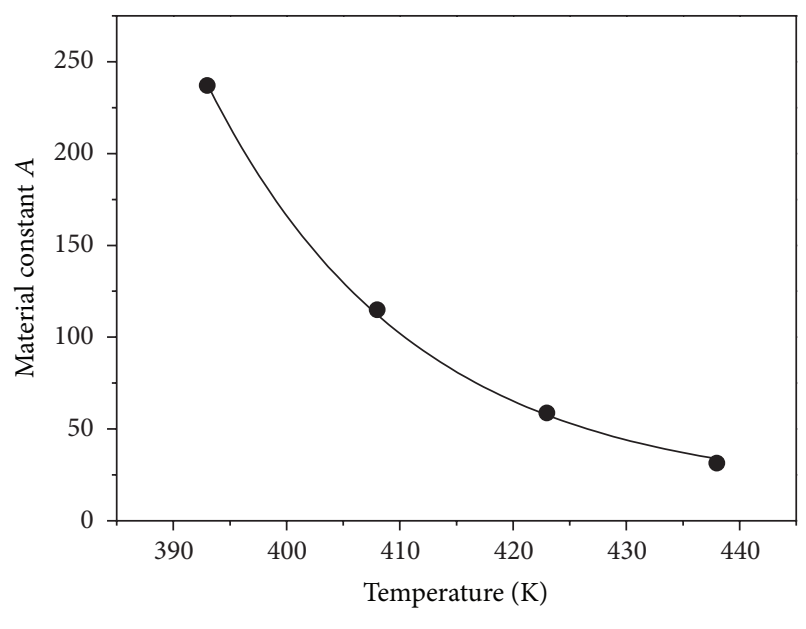

A-T curve

Figure 8: Correlation between tensile creep material constant and temperature.

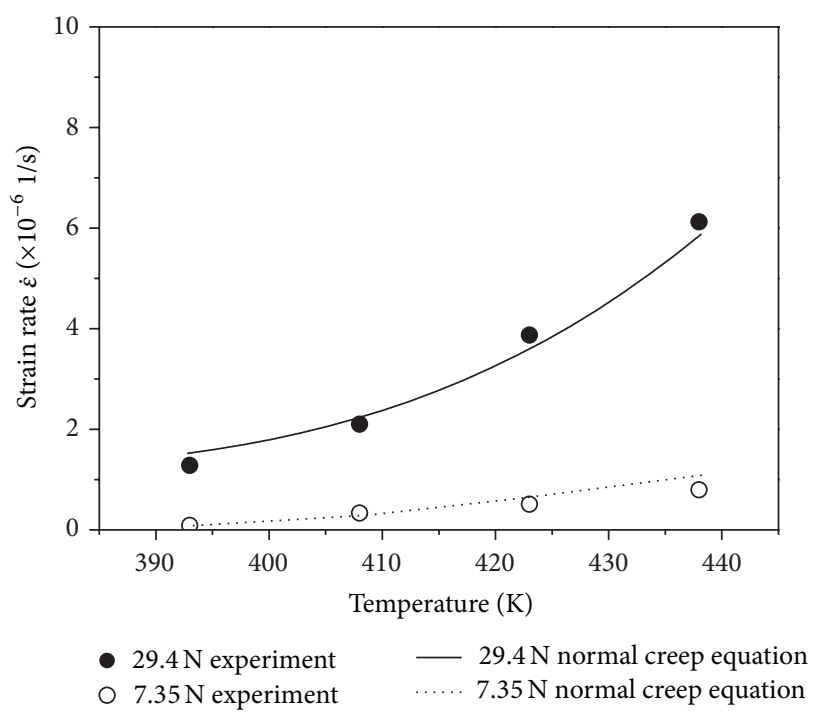

FIGURE 9: Correlation between strain rate and temperature in the tensile creep equation.

To improve the accuracy of these extracted parameters, the simplex optimization algorithm has been employed in this study to minimize the difference between measured strain rate and the strain rate data estimated from the initial trial parameters. All the extracted creep parameters mentioned previously are considered as the initial trial parameters in the optimization process. In the optimization procedure the following is assumed:

$$
\begin{gathered}
\text { strain rate: } \dot{\varepsilon}=(Q, n, \alpha, \beta, \omega), \\
\text { least square error: } \Delta^{2}=\sum_{i=1}^{8}\left(\dot{\varepsilon}_{i}-\dot{\varepsilon}_{\mathrm{ie}}\right)^{2},
\end{gathered}
$$

object function: $\min .\left(\Delta^{2}\right)$,

$\Delta$ : deviation between the estimated and experimental values, 


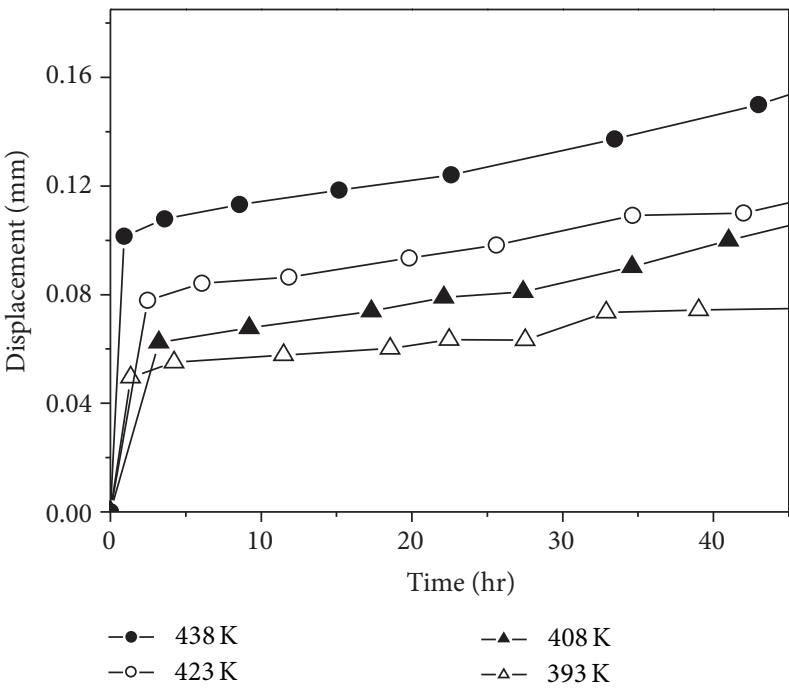

(a)

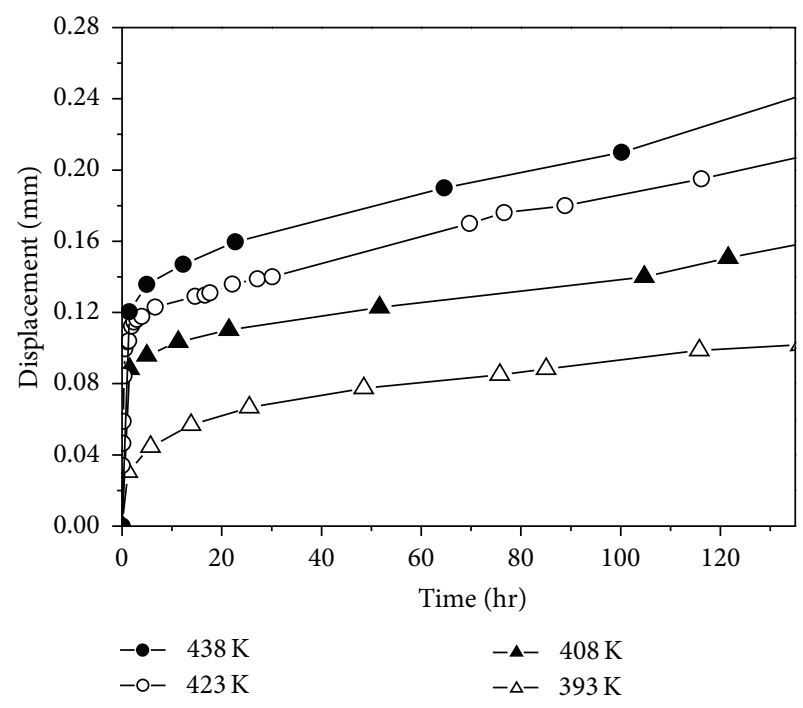

(b)

FIGURE 10: Correlation of displacement-time in the shear creep experiment under different loads: (a) $7.35 \mathrm{~N}$ load disc and (b) $29.4 \mathrm{~N}$ load disc.

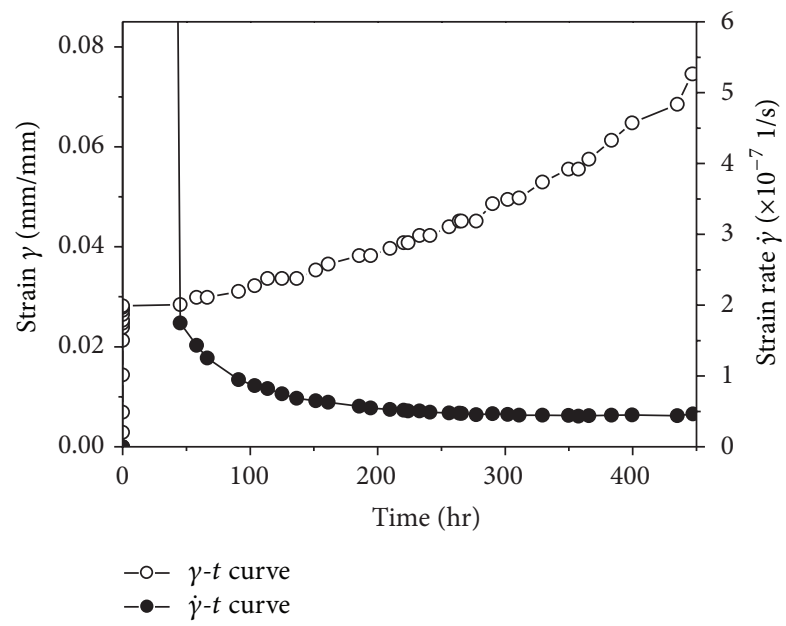

Figure 11: Correlation between strain-time and strain rate under a temperature of $408 \mathrm{~K}$ and a load of $7.35 \mathrm{~N}$ in the shear creep experiment.

$\dot{\varepsilon}_{i}$ : estimated tensile strain rate,

$\dot{\varepsilon}_{\mathrm{ie}}:$ measured tensile strain rate,

initial trial point:

$$
\begin{aligned}
& Q=64221.32, \quad n=1.954, \\
& \alpha=15.40, \quad \beta=6.39 \times 10^{11}, \\
& \omega=\left(-\frac{1}{18.04}\right) .
\end{aligned}
$$

The tensile creep parameters, that is, $n, Q, \alpha, \beta$, and $\omega$, for the $\mathrm{Sn} / 3.0 \mathrm{Ag} / 0.5 \mathrm{Cu}$ solder specimens converged from the simplex optimization method are $n=1.8640, Q=52154.52$, $\alpha=1.2507, \beta=6.3131 \times 10^{11}$, and $\omega=(-1 / 8.19)$. Based

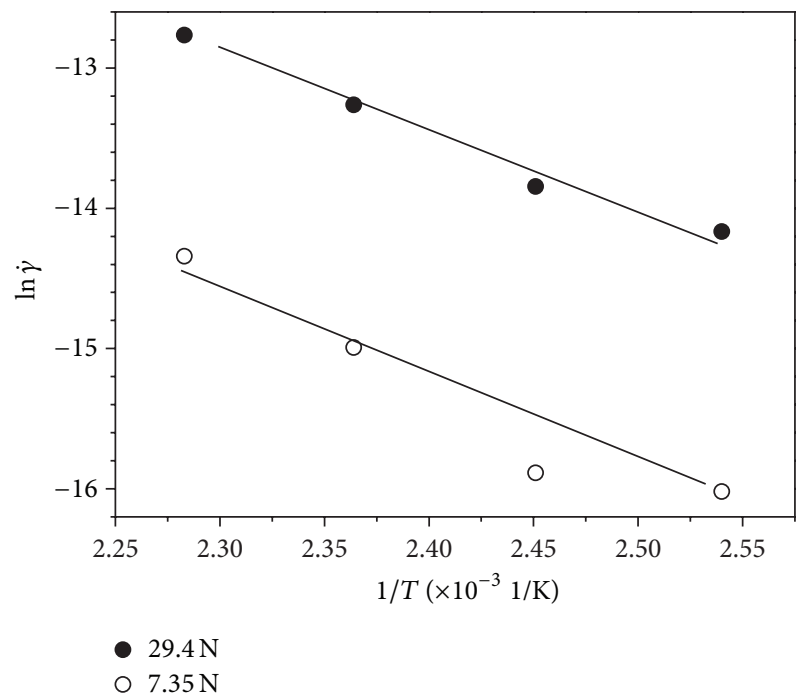

FIGURE 12: Correlation between the natural logarithm of the strain rate and the reciprocal of temperature in the shear creep experiment.

on the proposed algorithm and the measured creep data, the tensile creep equation for the $\mathrm{Sn} / 3.0 \mathrm{Ag} / 0.5 \mathrm{Cu}$ solder can be derived as

$$
\begin{aligned}
\dot{\varepsilon}= & {\left[1.25074+6.3131 \times 10^{11} \times e^{-T / 8.19}\right] } \\
& \times \sigma^{1.864} e^{-52154.52 / \mathrm{RT}} .
\end{aligned}
$$

A comparison between the temperature and estimated strain rate results for the specimens 1 (a) to $8(a)$ reveals a difference between $0.19 \%$ and $43.6 \%$ for the specimens with a loading of $7.35 \mathrm{~N}$ and a difference between $2.1 \%$ and $17.3 \%$ for the specimens with a loading of $29.4 \mathrm{~N}$ as shown in Figure 9. 


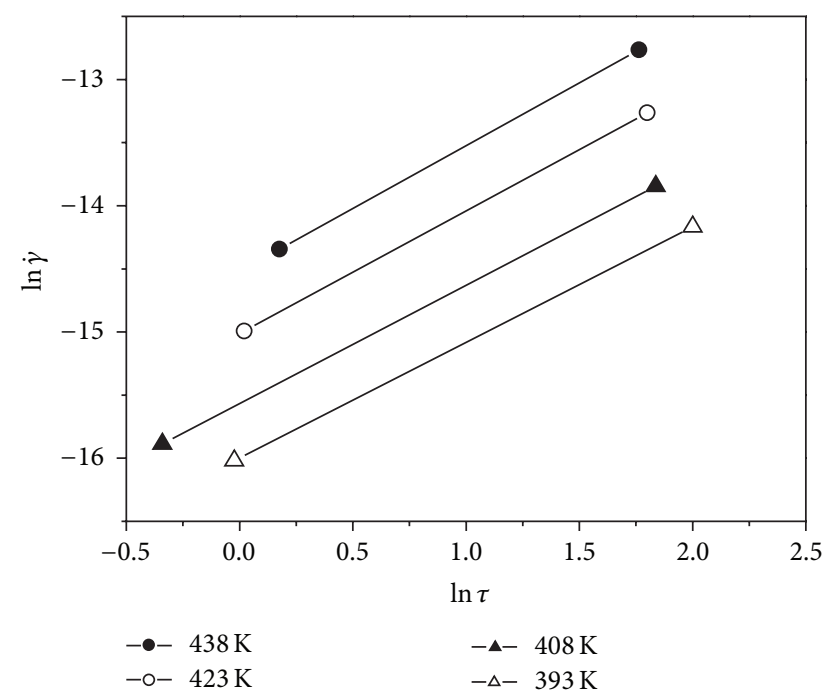

FIGURE 13: The correlation between the logarithm of strain rate and average stress for the shear creep test.

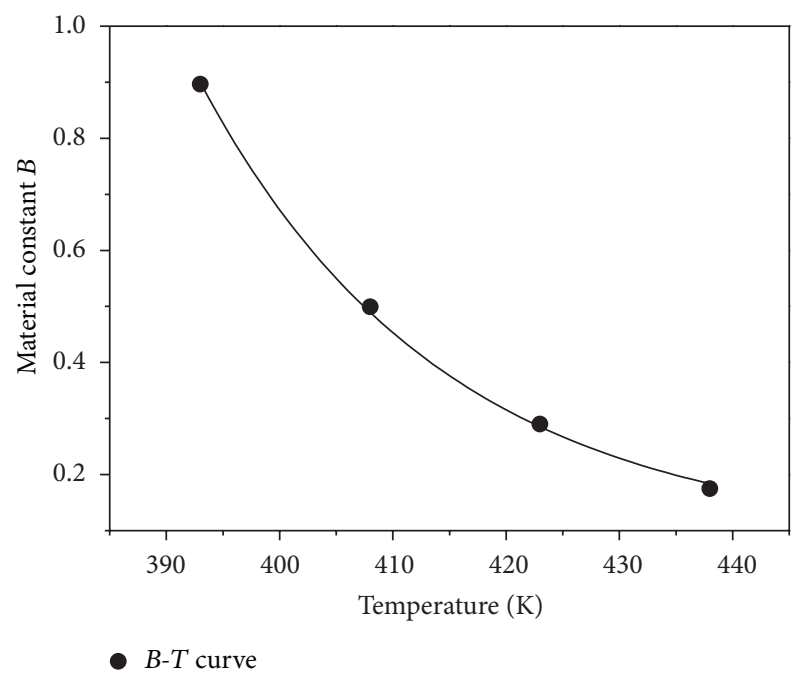

FIGURE 14: Correlation between shear creep material constant and temperature.

3.2. Shear Creep Experiment. Figure 10 shows the measured results of the shear creep specimens under the same creep loading condition as mentioned in the previous tensile test. For the specimens subjected to a load of $29.4 \mathrm{~N}$ with a loading temperature of $438 \mathrm{~K}$, the secondary creep stage occurs between 4.95 and 194 hours, and the creep extension of the shear specimens increases from $0.136 \mathrm{~mm}$ to $0.285 \mathrm{~mm}$. Figure 11 shows the variation of corresponding strain and strain rate with respect to loading time. The final secondary creep strain rate at the second stage is approximately $6.29 \times$ $10^{-8} 1 / \mathrm{sec}$. The recorded results of specimens $1(\mathrm{~b})$ to $8(\mathrm{~b})$ in the shear creep tests are listed in Table 3. Similarly, the correlation between $\ln \dot{\gamma}$ and $1 / T$ under loads of $7.35 \mathrm{~N}$ and $29.4 \mathrm{~N}$ is shown in Figure 12. From the slope values the $-Q / R$ values can be derived as -6879.823 and -5569.58 .
TABLE 3: Results of the shear creep specimen experiment.

\begin{tabular}{lcccc}
\hline No. & Load (N) & Temp. (K) & Average stress (MPa) & $\begin{array}{c}\text { Strain rate } \\
\left(\times 10^{-6} 1 / \mathrm{sec}\right)\end{array}$ \\
\hline 1 & & 393 & 0.977 & 0.0550 \\
2 & 7.35 & 405 & 0.711 & 0.0629 \\
3 & & 423 & 1.021 & 0.154 \\
4 & & 438 & 1.193 & 0.295 \\
\hline 5 & & 393 & 7.424 & 0.352 \\
6 & 29.4 & 405 & 6.282 & 0.485 \\
7 & 423 & 6.074 & 0.869 \\
8 & & 438 & 5.833 & 1.43 \\
\hline
\end{tabular}

And the average value is -6224.68 . Just by following the calculation used in the tensile test, an activation energy value of $51664.84(\mathrm{~J} / \mathrm{mol})$ is derived.

Figure 13 shows the correlation between the strain rate in the shear creep tests and the average shear stress. Four linear equations can be derived for the shear creep test results. They are

$$
\begin{array}{lll}
\ln \dot{\gamma}=0.92 & \ln \tau-16.00 & \text { when } T=393 \mathrm{~K}, \\
\ln \dot{\gamma}=0.94 & \ln \tau-15.57 & \text { when } T=408 \mathrm{~K}, \\
\ln \dot{\gamma}=0.97 & \ln \tau-15.01 & \text { when } T=423 \mathrm{~K}, \\
\ln \dot{\gamma}=0.99 & \ln \tau-14.52 & \text { when } T=438 \mathrm{~K} .
\end{array}
$$

Figure 14 shows the correlation between shear creep material constant and temperature. Following the process mentioned in the tensile creep test, the creep parameters in the shear creep equation can be approximated as $K=$ $0.084, \zeta=7.27$, and $\delta=(-1 / 21.47)$. All these approximated parameter values are considered as the initial trial values in the simplex optimization process to minimize the difference between the measured and estimated shear strain rates. The following is assumed:

$$
\begin{gathered}
\dot{\gamma}=\dot{\gamma}(\mathrm{Q}, m, K, \zeta, \delta), \\
\Delta^{2}=\sum_{i=1}^{8}\left(\dot{\gamma}_{i}-\dot{\gamma}_{\mathrm{ie}}\right)^{2},
\end{gathered}
$$

object function: $\min .\left(\Delta^{2}\right)$,

$\dot{\gamma}_{i}$ : estimated shear strain rate,

$\dot{\gamma}_{\mathrm{ie}}$ : shear strain rate from the experimental results.

A set of parameters is generated from the simplex optimization method; they are $m=0.9515, Q=58494.91$, $K=2.3705, \zeta=2.4639 \times 10^{9}$, and $\delta=(-1 / 17.99)$. Therefore, the following shear creep equation for the $\mathrm{Sn} / 3.0 \mathrm{Ag} / 0.5 \mathrm{Cu}$ solder can be derived:

$$
\begin{aligned}
\dot{\gamma}= & {\left[2.3705+2.4639 \times 10^{9} \times e^{-T / 17.99}\right] } \\
& \times \tau^{0.9515} e^{-58494.91 / \mathrm{RT}} .
\end{aligned}
$$




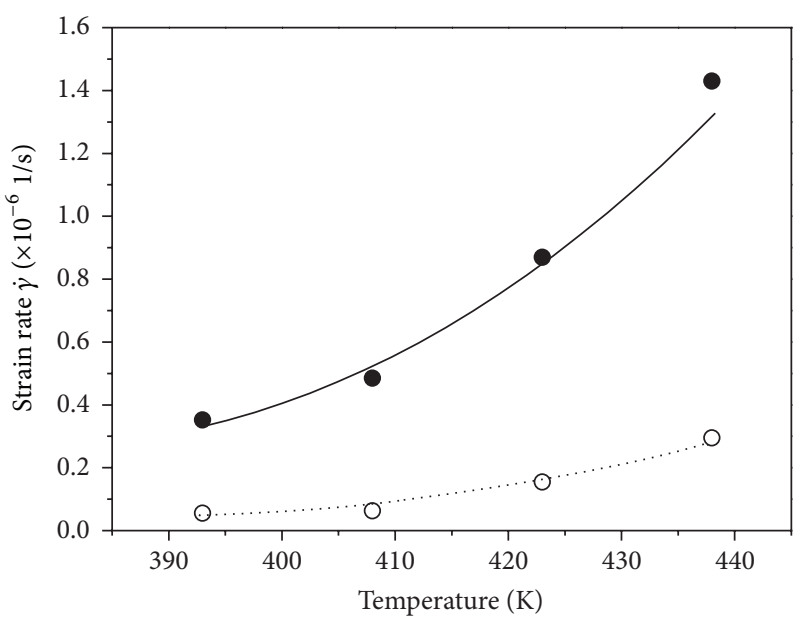

$\begin{array}{ll}-29.4 \mathrm{~N} \text { experiment } & -29.4 \mathrm{~N} \text { shear creep equation } \\ \text { - } 7.35 \mathrm{~N} \text { experiment } & \ldots . .35 \mathrm{~N} \text { shear creep equation }\end{array}$

FIGURE 15: Correlation between shear creep equations strain rate and temperature.

From a comparison between the experimental and the estimated strain rates for the shear creep specimens, that is, 1 (b) to 8 (b), a difference between 0.43 and $8.1 \%$ is found for the specimens with a load of $7.35 \mathrm{~N}$ as shown in Figure 15. A difference between 1 and $6 \%$ has been found for the specimens with a load of $29.4 \mathrm{~N}$.

\section{Conclusions}

The solder joint reliability is strongly affected by creep. This was validated by both simulation and experimental results, which show significantly higher occurrence of thermal failures of solder joints in high temperature aging tests. The high operation temperature induced creep phenomenon is the major cause of solder joint failure. Therefore, the reliability of solder packages under high operation temperature is highly dependent on solder joint creep property. The tensile and shear creep models of lead-free $\mathrm{Sn} / 3.0 \mathrm{Ag} / 0.5 \mathrm{Cu}$ solder material have been proposed in this study. Simplified tensile and shear tests can be used as a quick way of modeling the lead-free solder. Due to the diversity of the measured data, an optimization algorithm is proposed to extract the creep parameters in these creep equations. Experimental measurements and estimated strain rate results reveal that the proposed creep equations can provide reasonable accuracy.

The processes of extracting the creep parameters are specifically presented for illustrating the versatility of creep equation formulation. This result is useful for packaging reliable lead-free solder jointed assembly of high power laser or LED module packages. A wide variety of other applications of this proposed lead-free $\mathrm{Sn} / 3.0 \mathrm{Ag} / 0.5 \mathrm{Cu}$ solder creep model are expected.

\section{Conflict of Interests}

The authors declare that there is no conflict of interests regarding the publication of this paper.

\section{References}

[1] J. H. Lau and C. G. Harkins, "Stiffness of 'gull-wing' leads and solder joints for a plastic quad flat pack," IEEE Transactions on Components, Hybrids, and Manufacturing Technology, vol. 13, no. 1, pp. 124-130, 1990.

[2] J. H. Lau, Thermal Stress and Strain in Microelectronics Packaging, Van Nostrand Reinhold, New York, NY, USA, 1993.

[3] J. H. Lau, S. H. Pan, and C. Chang, "Creep analysis of solder bumped direct chip attach (DCA) on microvia build-up printed circuit board with underfill," in Proceedings of the International Symposium on Electronic Materials and Packaging (EMAP '00), pp. 127-135, 2000.

[4] J. H. L. Pang and D. Y. R. Chong, "Flip chip on board solder joint reliability analysis using 2-D and 3-D FEA models," IEEE Transactions on Advanced Packaging, vol. 24, no. 4, pp. 499-506, 2001.

[5] J. Lau, Z. Mei, S. Pang, C. Amsden, J. Rayner, and S. Pan, "Creep analysis and thermal-fatigue life prediction of the lead-free solder sealing ring of a photonic switch," Journal of Electronic Packaging, vol. 124, no. 4, pp. 403-410, 2002.

[6] J. H. Lau, S. W. R. Lee, S. H. Pan, and C. Chang, "Nonlineartime-dependent analysis of micro via-in-pad substrates for solder bumped flip chip applications," Journal of Electronic Packaging, vol. 124, no. 3, pp. 205-211, 2002.

[7] J. H. Lau and S.-W. R. Lee, "Modeling and analysis of 96.5Sn3.5Ag lead-free solder joints of wafer level chip scale package on buildup microvia printed circuit board," IEEE Transactions on Electronics Packaging Manufacturing, vol. 25, no. 1, pp. 51-58, 2002.

[8] J. W. Morris Jr., J. L. F. Goldstein, and Z. Mei, "Microstructure and mechanical properties of Sn-In and Sn-Bi solders," JOM, vol. 45, no. 7, pp. 25-27, 1993.

[9] W. Yang, R. W. Messler Jr., and L. E. Felton, "Microstructure evolution of eutectic Sn-Ag solder joints," Journal of Electronic Materials, vol. 23, no. 8, pp. 765-772, 1994.

[10] W. Yang, L. E. Felton, and R. W. Messler Jr., "The effect of soldering process variables on the microstructure and mechanical properties of eutectic $\mathrm{Sn}-\mathrm{Ag} / \mathrm{Cu}$ solder joints," Journal of Electronic Materials, vol. 24, no. 10, pp. 1465-1472, 1995.

[11] H. Yang, P. Deane, P. Magill, and K. L. Murty, "Creep deformation of $96.5 \mathrm{Sn}-3.5 \mathrm{Ag}$ solder joints in a flip chip package," in Proceedings of the 46th IEEE Electronic Components \& Technology Conference (ECTC '96), pp. 1136-1142, Orlando, Fla, USA, May 1996.

[12] A. M. Jackson, I. Artaki, and P. T. Vianco, "Manufacturing feasibility of several lead-free solders for electronic assembly," in Proceedings of the 7th International SAMPE Electronics Conference, pp. 381-393, Parsippany, NJ, USA, June 1994.

[13] P. T. Vianco, J. A. Rejent, and J. J. Martin, “The compression stress-strain behavior of Sn-Ag-Cu solder," JOM, vol. 55, no. 6, pp. 50-55, 2003.

[14] P. T. Vianco, J. A. Rejent, and P. F. Hlava, "Solid-state intermetallic compound layer growth between copper and 95.5Sn-3.9Ag$0.6 \mathrm{Cu}$ solder," Journal of Electronic Materials, vol. 33, no. 9, pp. 991-1004, 2004.

[15] P. T. Vianco, J. A. Rejent, and A. C. Kilgo, "Creep behavior of the ternary 95.5Sn-3.9Ag-0.6Cu solder-part I: as-cast condition," Journal of Electronic Materials, vol. 33, no. 11, pp. 1389-1400, 2004.

[16] E. P. Lopez, P. T. Vianco, and J. A. Rejent, "Solderability testing of $\mathrm{Sn}-\mathrm{Ag}-\mathrm{XCu} \mathrm{Pb}$-free solders on copper and $\mathrm{Au}-\mathrm{Ni}$-Plated Kovar 
substrates," Journal of Electronic Materials, vol. 34, no. 3, pp. 299-310, 2005.

[17] M. T. Shen and T. Mao, Laser diode module residual stress and creep effect [Ph.D. dissertation], Graduate Institute of Mechanical Engineering, National Sun Yat-Sen University, 2000.

[18] F. Gao, H. Nishikawa, T. Takemoto, and J. Qu, “Temperature dependence of mechanical properties of individual phases in Sn-3.0Ag-0.5Cu lead-free solder alloy," in Proceedings of the 58th Electronic Components and Technology Conference (ECTC '08), pp. 466-471, Miami, Fla, USA, May 2008. 

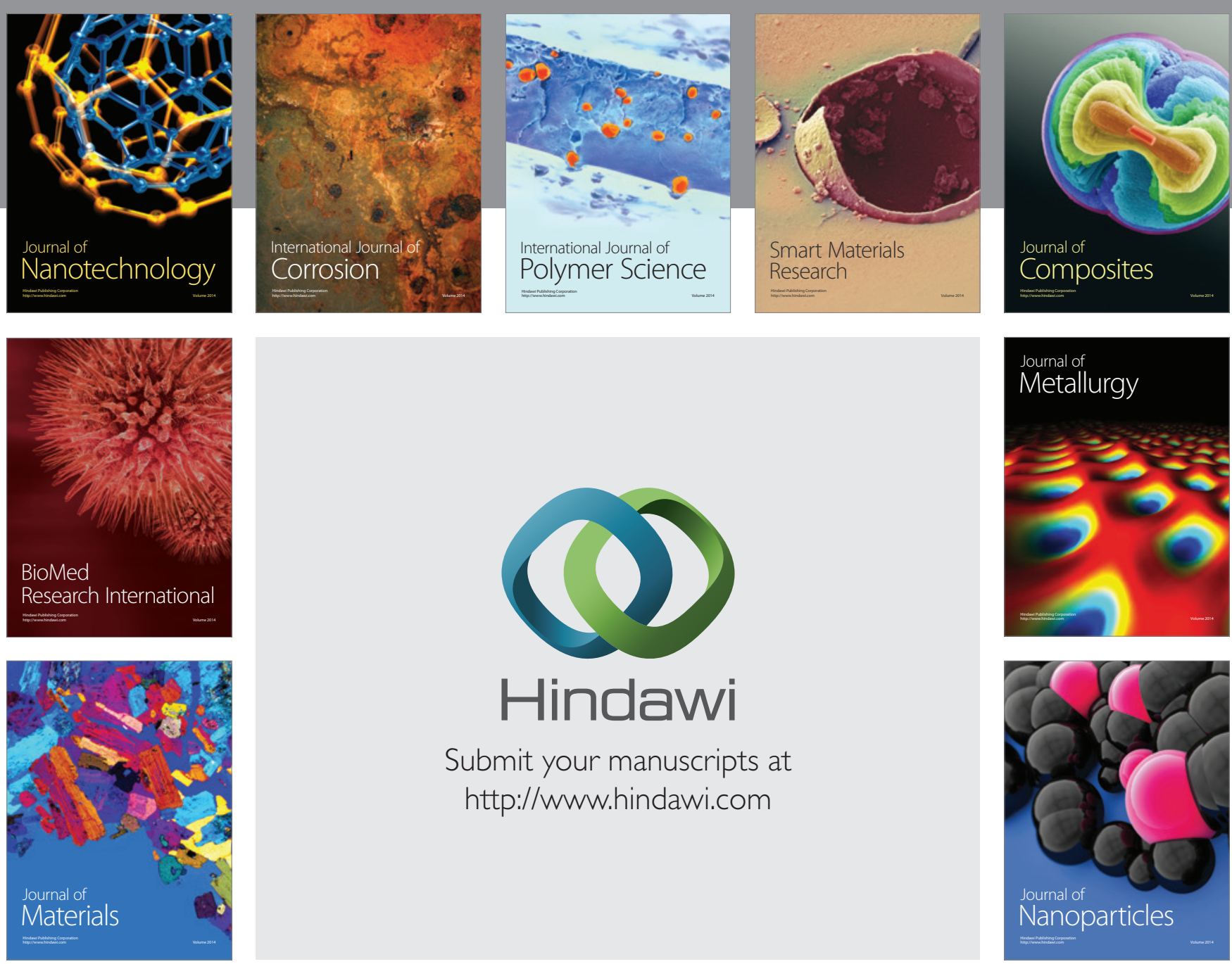

Submit your manuscripts at http://www.hindawi.com
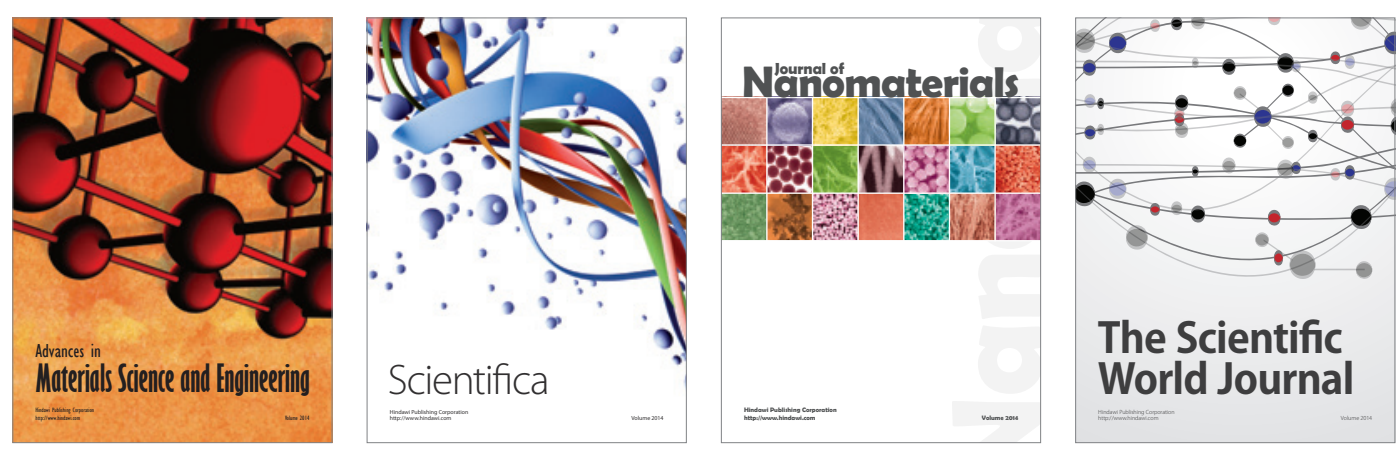

\section{The Scientific World Journal}
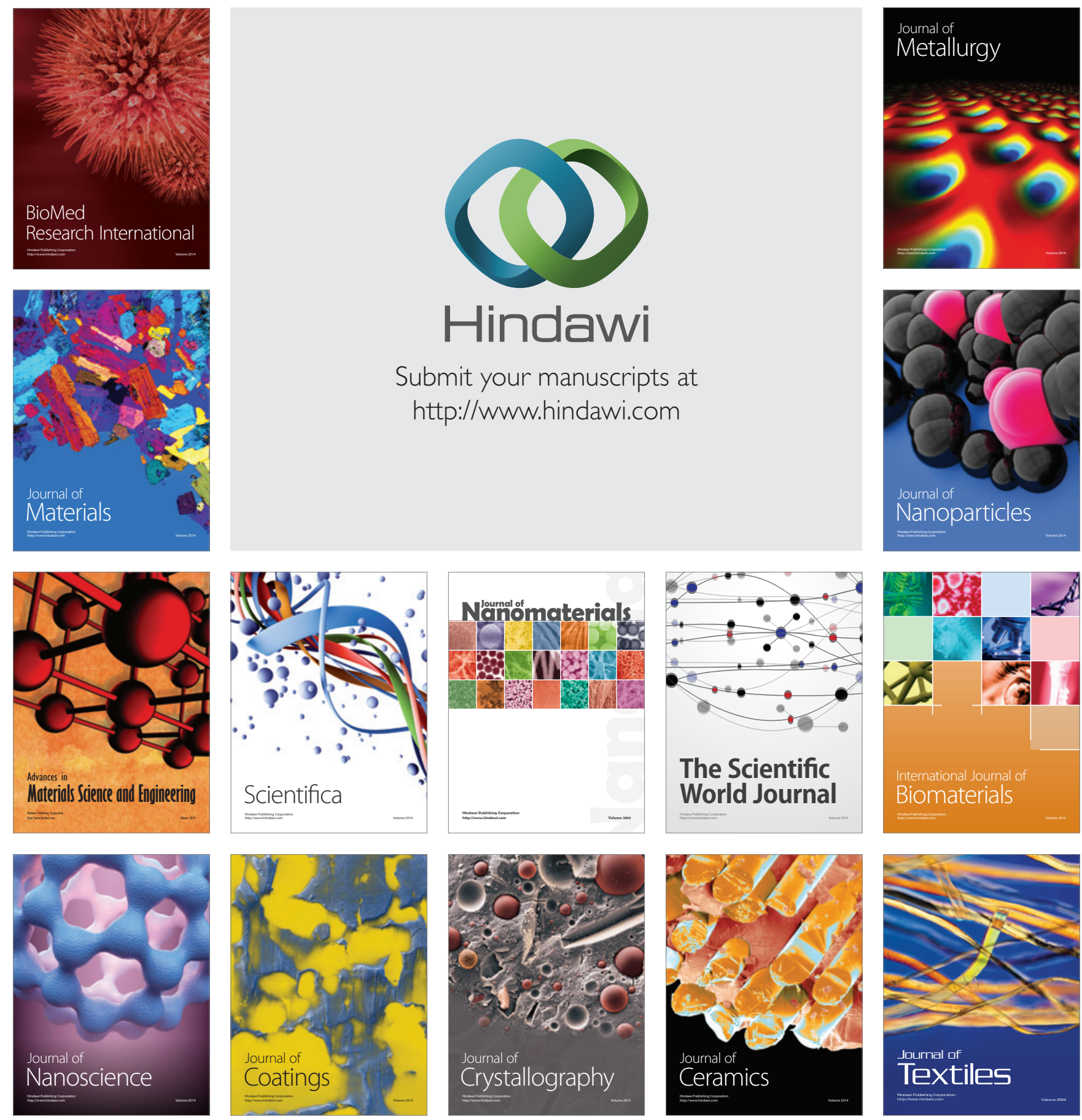